\title{
GROWTH CURVE PREDICTION OF HOLSTEIN-FRESIAN BULLS USING DIFFERENT NON-LINEAR MODEL FUNCTIONS
}

\author{
TUTKUN, M. \\ Department of Animal Science, Faculty of Agricultural, Dicle University \\ 21280 Diyarbakir, Turkey \\ (e-mail: tutkunmuhittin@yahoo.com; phone: +90-412-241-1000; fax: +90-412-241-1048) \\ (Received $31^{\text {st }}$ Jan 2019; accepted $28^{\text {th }}$ Feb 2019)
}

\begin{abstract}
This study aimed to determine the best model to explain the variations in the live weight of Holstein bulls using non-linear function models such as Brody's, Gompertz's and Richards Logistic. For this purpose, live weight records of 51 Holstein Fresian male calves reared in Dicle University Cattle Research Farm were used. In order to estimate the best model, the coefficient of determination $\left(R^{2}\right)$ and the residual mean squares (RMS) statistics were utilized. The coefficient of determination $\left(R^{2}\right)$ for Gompertz's, Richards Logistic and von Bertalanffy models were found to be 0.999, 0.999, 0.998 and 0.999 respectively. Residual mean squared were found to be $21.41,16.82,50.94$ and 22.21 , respectively. As a result, the Richards model used in the study was found to be the best fitted model based on RMS and $\mathrm{R}^{2}$ criteria. It is the more suitable model due to its accurate ability to predict mature weight, which is an important selection goal.
\end{abstract}

Keywords: bodyweight, growth, Holstein bull, inflection point, Richards

\section{Introduction}

The increase in size, number or mass with time is the primary definition of growth but does not include the phenomenology and etiology of growth, such as the energy transactions in the growing animal including metabolism, nutrition and genetics (Parks, 1982).

Growth is usually defined as an increase in tissue mass caused by hyperplasia early in life and hypertrophy later in life (Owens et al., 1995). The accurate knowledge of the growth curve is important due to its relation with the efficiency of production (Fitzhugh, 1976).

Prediction of growth in animals can be found by age-weight graphical plotting using mathematical models (Bathaei and Leory 1996).

Growth curve study in cattle has mainly used non-linear models that relate the animal weights to ages (Garnero et al., 2006; Forni et al., 2009; Souza et al., 2010).

In beef cattle, different equations for growth model have been used and compared in Hereford (Brown et al., 1976), Angus (Beltran et al., 1992), Retinta Cattle (López de Torre et al., 1992), Belgian Blue (Behr et al., 2001), Salers (Garcia et al., 2008) and Nelore (Forni et al., 2009).

The many equations that have been used to predict growth for cattle include Gompertz, Robertson's logistic, Brody, Bertalanfy, Feller, Weiss and Kavanau, Fitzhugh, Richards, Laird, and Parks equations. Detailed descriptions for the models were summarized by Parks in 1982. The most used models to describe growth patterns in beef cattle are: Brody, Bertalanfy, logistic, Gompertz and Richards (Brown et al., 1976, Fitzhugh Jr 1976). Difficulties in obtaining convergences within Richards and Janoschek functions have been reported by Sarmento et al. (2006).

The objective of the study was to assess and compare the non-linear models by Gompertz, Richards and Logistic for goodness of fit of the weight-age data for Holstein Frisan bulls. 


\section{Materials and methods}

The experiment was conducted in Dicle University, Cattle Research Center in Diyarbakir Province, Turkey (37 57'41 N and 40 $133^{\prime} 54 \mathrm{E}, 650 \mathrm{~m}$ asl) (Figure 1).

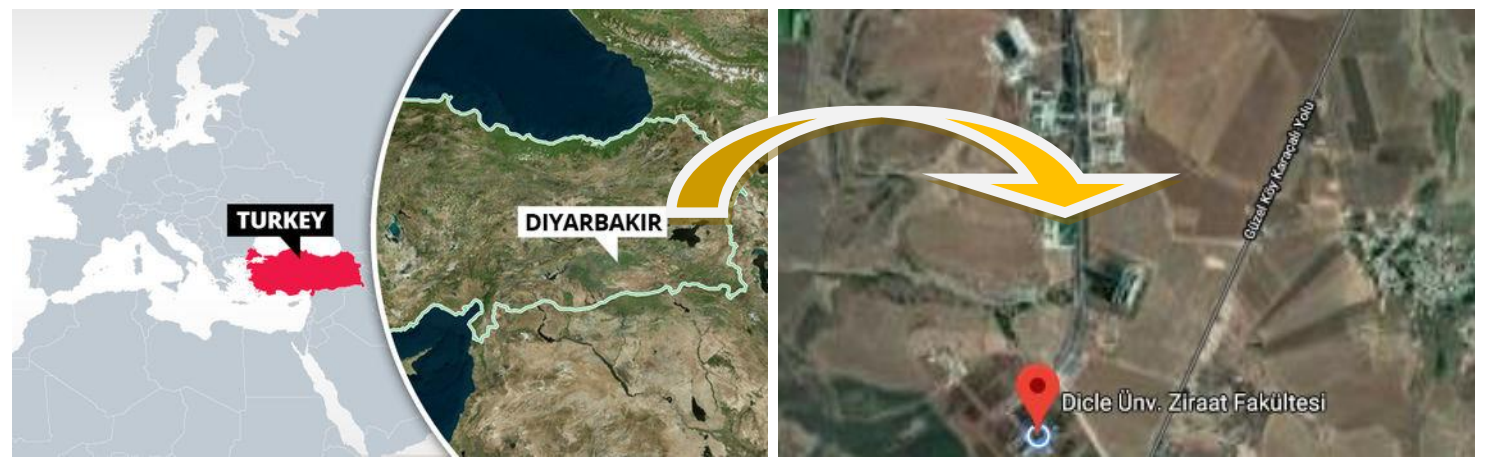

Figure 1. Study location map

The material of this study consisted of monthly live weight records of 51 Holstein Fresian male calves from 4th. to16th. month reared in Dicle University Cattle Research Farm. The research did not require the Bioethical Committee's Certification.

The study material consisted of monthly live weight and body measurement records of 51 male Holstein-Friesian bulls collected between the years 2016 and 2018. The study was carried out in two different locations. First stage was between the days born120 d. in private farm and second was in Cattle Research Farm of Dicle University. Calves born in private dairy farm received milk as much as $10 \%$ of their body weight with starter feed after 2 weeks. Calves were weaned at the 9th of weeks. Different amounts of concentrate and roughage were provided ad libitum to the bulls considering the average live weights obtained from the monthly measurements.

All data of means and standard errors of weights during different age stages were analyzed using SPSS (Statistical Package for the Social Sciences, version 10). Nonlinear models of Gompertz (1825), Richards (1959), von Bertalanffy (1957) and the Logistic model introduced by Verhulst (1838) were fitted to the weight-age data using non-linear regression procedure option.

Assessment of goodness of fit among three models was applied having the highest determination coefficient $\left(\mathrm{R}^{2}\right)$ percentage. Models parameters $(\mathrm{A}, \mathrm{b}, \mathrm{k}$, and $\mathrm{M})$ were iterated at a set of a maximum of 150 times the initial of their values using the Levenberg-Marquardt method option.

The used model functions (Gompertz, Richards, Logistic and von Bertalanffy) to fit Holstein male growth curve present in Table 1.

Table 1. Non-linear functions used for modeling the growth curves [Yt=weight $(\mathrm{kg})$ at time (month). $A=$ asymptotic weight. $b=$ scale parameter. $k=$ maturing index. $e=$ logarithm base. $m=$ inflection point. $\varepsilon=$ random error $]$

\begin{tabular}{c|c}
\hline Model & Function \\
\hline Gompertz & $\mathrm{Y}_{\mathrm{t}}=\mathrm{Ae}-\mathrm{b} \exp (-\mathrm{kt})+\varepsilon$ \\
Richards & $\mathrm{Y}_{\mathrm{t}}=\mathrm{A}\left(1-\mathrm{be}^{-\mathrm{kt}}\right)^{\mathrm{m}}+\varepsilon$ \\
Logistic & $\mathrm{Y}_{\mathrm{t}}=\mathrm{A}\left(1+\mathrm{e}^{(-\mathrm{kt})}\right)^{-1}+\varepsilon$ \\
Von Bertalanffy & $\mathrm{Y}_{\mathrm{t}}=\mathrm{A} *(1-\mathrm{B} * \exp (-\mathrm{k} * \mathrm{t}))^{3}$ \\
\hline
\end{tabular}


In the mathematical expressions, yt represents the weight of the animal at a given age $(\mathrm{t})$; parameter $\mathrm{A}$ is the asymptotic weight, if $\mathrm{t} \rightarrow \infty$; when the adult weight of the animal is not reached, this reflects in an estimate of the weight of the last weighings; $b$ is a constant without biological interpretation, but it is important to model the sigmoidal format of the growth curve from birth $(t=0)$ until the adult age of the animal $(t \rightarrow \infty)$; $\mathrm{K}$ is the maturity index, which expresses the ratio of the maximum growth rate in relation to the adult size, where lower $\mathrm{k}$ values indicate delayed maturities and higher $\mathrm{k}$ values indicate accelerated maturity; $M$ is the parameter that shapes the curve; e is the natural base logarithm; the L parameter has no biological meaning, but together with $\mathrm{K}$ constitutes $\mathrm{b}$, which has the function of modeling the sigmoidal curve; and $\varepsilon$ represents the random error associated with each weighing (Marinho et al., 2013)

The statistical criteria and biological interpretation of the parameters were used to compare the non-linear models for goodness of fit. The statistical criterias were mean square error (MSE) and coefficient of determination $\left(\mathrm{R}^{2}\right)$.

Weight and age at the point of inflection were calculated as Eq.1 for logistic; Eq.2 for Gompertz; and Eq.3 for Richards.

$$
\begin{gathered}
Y_{i}=A / 2 \text { and } t_{i}=\ln (B) / k \\
Y_{i}=A / e \text { and } t_{i}=\ln (B) / k \\
Y_{i}=A /(d+1)^{1 / d} \text { and } t_{i}=-1 / k * \ln |d / B|
\end{gathered}
$$

By using the three obtained equations in terms of the formula, then the predicted growth curves were plotted and presented with observed live weight data.

\section{Results}

The observed live weight of Holstein bulls and standard error was shown below. According to the data obtained an average birth weight and final live weight was found as $33.41 \pm 0.84 \mathrm{~kg}$ and $553.66 \pm 7.41$ respectively during the 16 month of age (Table 2).

Growth curve parameters (A, b and $\mathrm{K}$ ) from tree non-linear (Gompertz, Richards and Logistic) models with their relative determination coefficient $\left(\mathrm{R}^{2}\right)$ and residual mean squared values was shown in Table 3.

The models explaining the growth of Holstein bulls according to $\mathrm{R}^{2}$ and RMS values were arranged in terms of efficiency as Gompertz, Richards and Logistic. Comparison of the models based on the coefficient of determination $\left(\mathrm{R}^{2}\right)$ showed that Richards model led to an improved fit of data compared to Gompertz Logistic and von Bertalanffy equations $(0.999,0.998$ and 0.997 and 0.999 respectively). The Richards and von Bertalanffy model having the highest coefficient of determination (0.999) and the lowest residual mean squared (16.82and 22.21) value was the best model explaining the growth of the Holstein bulls (Table 3). Considering that lowest RMS value determines a greater reliability of the model, so Richards function have the best fit with 16.82 RMS value. The highest value for the coefficient A was obtained with von Bertalanffy model. The value of the coefficient $\mathrm{K}$ was found similar in all models. 
The results indicate that all the growth functions were easily fitted to the observed data by nonlinear regression. The estimated growth curve patterns compared with the observed live weights for Holstein bulls was shown in Figure 2.

Table 2. Observed means and standard error of Holstein bulls weights by age

\begin{tabular}{c|c|c|c|c}
\hline \multicolumn{2}{c}{} & \multicolumn{3}{c}{ 95\% Confidence Interval } \\
\hline Age(Month) & Weight (Kg) & SE & Lower Bound & Upper Bound \\
\hline Birth & 33.41 & 0.84 & 24 & 42 \\
1 & 48.38 & 1.05 & 32 & 59 \\
2 & 68.34 & 1.36 & 42 & 83 \\
3 & 86.21 & 1.57 & 53 & 101 \\
4 & 99.91 & 2.98 & 65 & 126 \\
5 & 135.01 & 3.25 & 100 & 168 \\
6 & 170.99 & 3.51 & 132 & 205 \\
7 & 207.52 & 3.72 & 162 & 247 \\
8 & 244.42 & 4.07 & 193 & 282 \\
9 & 281.38 & 4.33 & 230 & 320 \\
10 & 317.16 & 4.56 & 260 & 358 \\
11 & 355.52 & 5.51 & 298 & 408 \\
12 & 394.24 & 5.85 & 335 & 455 \\
13 & 432.86 & 6.15 & 372 & 497 \\
14 & 471.72 & 6.67 & 409 & 542 \\
15 & 516.38 & 7.25 & 446 & 580 \\
16 & 553.66 & 7.41 & 486 & 601 \\
\hline
\end{tabular}

Table 3. Means and standard error of Holstein-Friesan bulls growth curve parameters, coefficients of determination and residual mean square by different non-linear models

\begin{tabular}{c|c|c|c|c|c|c}
\hline Model & $\mathbf{A}$ & $\mathbf{b}$ & $\mathbf{K}$ & $\mathbf{M}$ & $\mathbf{R}^{\mathbf{2}}$ & $\mathbf{R M S}$ \\
\hline Gompertz & $986.440 \pm 3.403$ & $3.354 \pm 0.033$ & $0.004 \pm 0.00$ & - & 0.998 & 21.41 \\
Richards & $1110.243 \pm 51.881$ & $0.299 \pm 0.02$ & $0.003 \pm 0.00$ & $10.632 \pm 17.4$ & 0.999 & 16.82 \\
Logistic & $672.940 \pm 25.817$ & $13.760 \pm 0.696$ & $0.008 \pm 0.00$ & - & 0.997 & 50.94 \\
Bertalanffy & $1565.604 \pm 134.683$ & $0.737 \pm 0.005$ & $0.002 \pm 0.00$ & - & 0.999 & 22.21 \\
\hline
\end{tabular}

A: asymptotic weight. b: scale parameter( constant of integration) K: maturity rate. R2: determination coefficient. RMS: residual mean squared



Figure 2. Growth curve obtained by the avarage of weight observed and weight stated by Gompertz, Richards, Logisticand von Bertalanffy models in different ages. 


\section{Inflection point traits}

The estimates of weight and age at the inflection point was reported in Table 4. Age at the inflection point $\left(\mathrm{t}_{\mathrm{i}}\right)$ is the maximum growth rate longitudinal time frame of live weight. Different from the values of $t_{i}$ estimated by using Richards model (400.14 days) and von Bertalanffy (396.72 days) were found similar to each other, those calculated using Gompertz and Logistic were lower and similar to each other (327.72 and 306.75 days, respectively). Moreover, the highest value of ti was obtained using the Richards model (400.14 days) with a Wi of $545.01 \mathrm{~kg}$. By using Gompertz, Logistic and von Bertalanffy equations the values of Yi obtained as $362.89,463.88$ and $336.47 \mathrm{~kg}$, respectively (Figure 3).

Table 4. The inflection point traits by different non-linear models

\begin{tabular}{c|c|c|c|c}
\hline & Gompertz & Richards & Logistic & von Bertalanffy \\
\hline Weight at the inflection point $\left(\mathrm{Y}_{\mathrm{i}}\right), \mathrm{kg}$ & 362.89 & 545.01 & 336.47 & 463.88 \\
Age at the inflection point $\left(\mathrm{t}_{\mathrm{i}}\right)$, day & 306.75 & 400.14 & 327.72 & 396.72 \\
Shape parameter $(\mathrm{d})$ & - & 10.63 & - & - \\
\hline
\end{tabular}

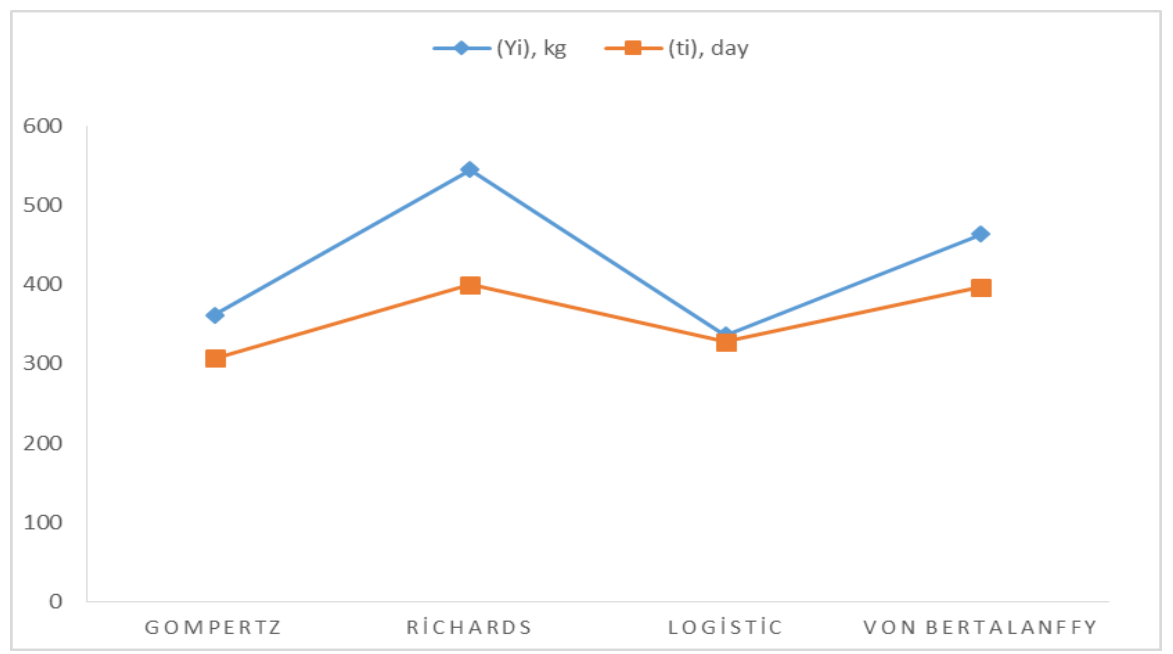

Figure 3. The inflection point traits $\left(Y_{i}\right.$ and $\left.w_{i}\right)$ curve by different non-linear models

The Logistic and Gompertz models overestimate the initial weights as 38\% and $4 \%$ respectively. The Richards and Von Bertalanffy underestimate as $2.39 \%$ and $12.27 \%$ respectively. Overestimation of the final weights by Gompertz and von Bertalanffy was $11 \%$ and 4.47 , underestimation of those was $5.92 \%$ and $3.90 \%$ respectively (Table 5).

Table 5. Overestimation and underestimation of initial and final live-weights by different non-linear models (OE: Overestimation; UE: Underestimation)

\begin{tabular}{c|c|c|c|c}
\hline \multicolumn{2}{c|}{ Initial live weights } & \multicolumn{2}{c}{ Final live weights } \\
\hline Models & OE\% & UE\% & OE\% & UE\% \\
Logistic & 38 & - & - & 5.92 \\
Gompertz & 4 & - & 11 & - \\
Richards & - & 2.39 & - & 3.90 \\
von Bertalanffy & - & 12.27 & 12.27 & - \\
\hline
\end{tabular}


According to different non-linear models, over-underestimate curve of initial and final live weights plot was shown in Figure 4.

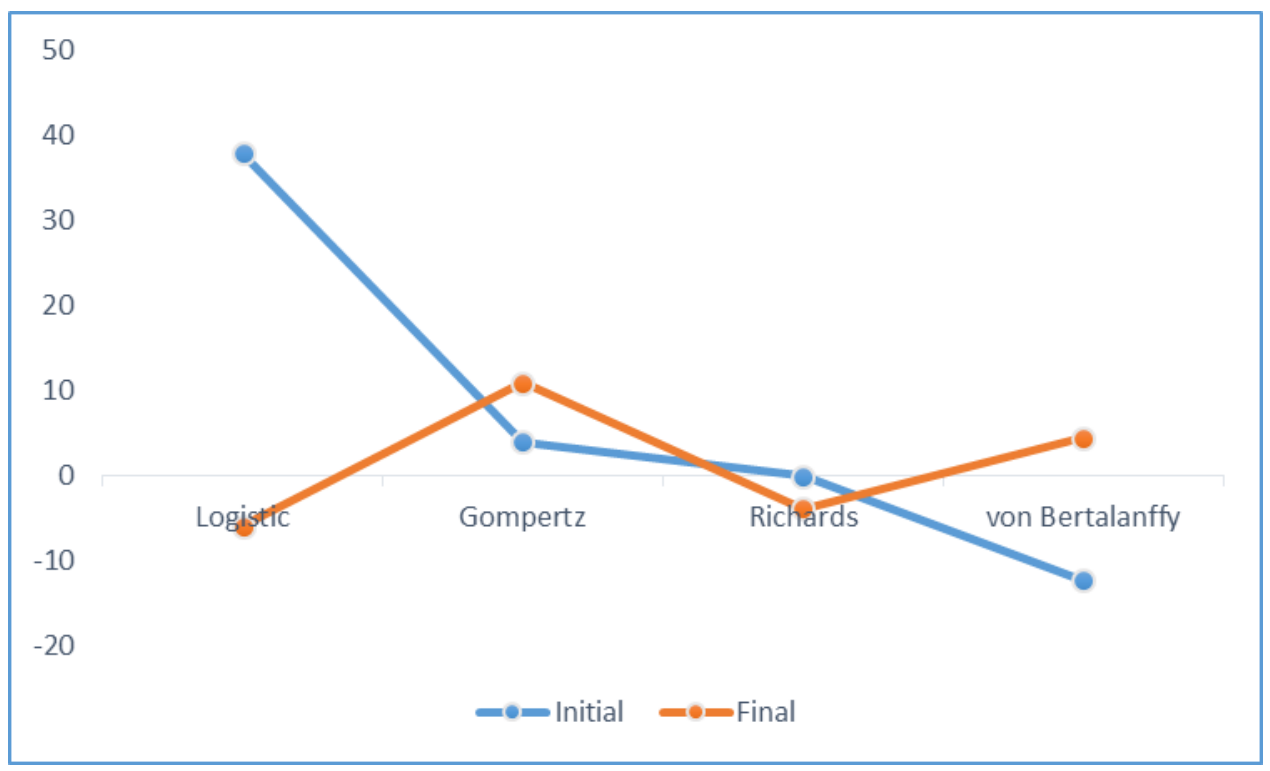

Figure 4. Over-underestimate curve of initial and final live weights plot

\section{Discussion}

According to findings Richards and Gompertz model was found the best overall fit for the growth of Holstein bulls.

Selvaggi et al. (2017) reported that the Logistic and Richards models provided the best fit, being useful to study the growth of Padolica bulls. Various studies reported that different growth functions gave a best data fit in cattle. In particular, DeNise and Brinks (1985) and Beltran et al. (1992) reported the Richards function as the best for cattle. Conversely, Mazzini et al. (2003) stated that Brody and Richards functions were inadequate to describe the growth pattern of Hereford bulls. Mgberel and Olutogun (2002) stated that Richards model with least residual mean squares was the best fit to the observed growth pattern of male and female N'Dama cattle.

Koşkan and Özkaya (2014) obtained the highest $\mathrm{R}^{2}$ values of 0.992 and 0.991 respectively by using the Logistic and Gompertz model.

In a recent study conducted by Gano et al. (2015) on Parda de Montaña breed, the Richards function provided the best goodness of fit as also suggested by DeNise and Brinks (1985) and Doren et al. (1989). Furthermore, Gano et al. (2015) reported that the von Bertalanffy function also described the dataset satisfactorily, whereas the logistic equation had the worst fit. Goldberg and Ravagnolo (2015) analyzed the growth curves for Angus cows using different nonlinear models and the results showed that the Richards model was the best to fit the data

The best estimations according to the birth weights were obtained from the Gompertz and Richards models, even if the estimations were lower by $R$ and higher by $G$ than the actual weights. On the other hand, in their study Perotto et al. (1992) stated that the G and $\mathrm{L}$ models estimate birth weights higher than the actual values and the $\mathrm{R}$ model would be more convenient to estimate birth weights. 


\section{Conclusions}

On the basis of our results, Richards model is the best fitted model based on RMS and $\mathrm{R}^{2}$ criterias which is adequate to establish mean growth pattern of Holstein bulls. Although Richards is a four-parameter model having more computational difficulty, it is the more suitable one due to its accurate ability in predicting mature weight, which is an important selection goal. The growth curve parameters will provide an opportunity to design selection strategies since they may be included in genetic improvement programs as successfully done in other species as well. Richards growth curve model should be used for the other cattle genotypes because there are differences in their growth patterns.

\section{REFERENCES}

[1] Bathaei, S. S., Leroy, P. L. (1996): Growth and mature weight of Mehraban Iranian fat tailed sheep. - Small Rum Res 22: 155-162.

[2] Behr. V., Hornick, J. L., Cabaraux, J. F., Alvarez, A., Istasse, L. (2001): Growth patterns of Belgian Blue replacement heifers and growing males in commercial farms. - Live Prod Sci 71: 121-130.

[3] Beltran, J. J., Butts, W.T., Olson, T.A., Koger, M. (1992): Growth patterns of two lines of Angus cattle selected using predicted growth parameters. - J Anim Sci 70: $734-741$

[4] Brown, J. E., Fitzhugh, H. A., Cartwright, T. C. (1976): A comparison of nonlinear models for 356 describing weight-age relationships in cattle. - J Anim Sci 42: 810 -818.

[5] DeNise, R. S. K., Brinks, J. S. (1985): Genetic and environmental aspects of growth curve parameters in beef cows. - J Anim Sci 61: 1431-1440.

[6] Fitzhugh, H. A. Jr. (1976): Analysis of growth curves and strategies for altering their shape. - 382 J Anim Sci 42: 1036-1051.

[7] Forni, S., Piles, M., Blasco, A., Varona. L., Oliveira, H. N. (2009): Comparison of different nonlinear functions to describe Nelore cattle growth. - J Anim Sci 87: 496 -506.

[8] Gano, G., Blanco, M., Casasús, I., Cortés-Lacruz, X., Villalba, D. (2015): Comparison of B-splines and non-linear functions to describe growth patterns and predict mature weight of female beef cattle. - Anim Prod Sci 2015, doi:10.1071/ AN15089

[9] Garcia, F., Sainz, R. D., Agabriel, J., Barioni, L. G, Oltjen, J. W. (2008): Comparative analysis of two dynamic mechanistic models of beef cattle growth. - Anim Feed Sci Technol 143: 220-241.

[10] Garnero, A. D. V., Marcondes, C. R., Gunski, R. J. (2006): Genetic trends in the expected progeny difference of the asymptotic weight of Nelore females. - Genet Mol Biol 29: 648-652.

[11] Goldberg, V., Ravagnolo, O. (2015): Description of the growth curve for Angus pasturefed cows under extensive systems. - J Anim Sci 93, 4285-4290.

[12] Gompertz, B. (1825): On the nature of the function expressive of the law of human mortality, and on a new mode of determining the value of life contingencies. Philosophical transactions of the Royal Society of London 115: 513-585.

[13] Koskan, Ö., Özkaya, S. (2014): Determination of growth curves of female Holstein calves using five non-linear models. - Pak J Agri Sci 51(1): 225-228

[14] López de Torre, G., Candotti, J. J., Reverter, A., Bellido, M. M., Vasco P. (1992): Effects of growth curve parameters on cow efficiency. - J Anim Sci 70: 2668-2672.

[15] Marinho, K. N. S., Freitas, A. R., Falcão, A. J. S., Dias, F. E. F. (2013): Nonlinear models for fitting growth curves of Nellore cows reared in the Amazon Biome. - R Bras Zootec 42: 645-650. 
[16] Mazzini, A. R., Muniz, J. A., Aquino, L. H., Silva, F. F. (2003): Análiseda curva decrescimento de machos Hereford. - Ciênc Agrotéc 27: 1105 -1112.

[17] Mgberel, O. O., Olutogun, O. (2002): A comparison of non-linear models for describing weight-age relationships in N'Dama Cattle. - J. Appl. Anim. Res. 22 (2002): 225-230

[18] Owens, F. N., Gill, D. R., Secrist, D. S., Coleman, S. W. (1995): Review of some aspects of growth and 428 development of feedlot cattle. - J Anim Sci 73: 3152-3172.

[19] Parks, J. R. (1982): A theory of feeding and growth of animals. - Advanced Series in Agricultural Science Springer-Verlag, Berlin, Germany: 322.

[20] Perotto, D., Cue, R. I., Lee, A. J. (1992): Comparison of nonlinear functions for describing the growth curve of three genotypes of dairy cattle. - Can J Anim Sci 72: 773782.

[21] Richards, J. F. (1959): A flexible growth function for empiricaluse. - Journal of Experimental Botany 10: $290-300$.

[22] Sarmento, J. L. R., Rezazzi, A. J., Souza, W. H., Torres, R. A., Breda, F.C. (2006): Estudo da curva de crescimento de ovinos Santa Inês. - R Bras Zootec 35: 435-442.

[23] Selvaggi, M., Laudadio, V., Gabriella, A., Alessandro, D., Dario, C. (2016): Comparison on accuracy of different nonlinear models in predicting growth of Podolica bulls. - Jap Soc Animal Science 88(8):1128-1133

[24] Souza, L. A., Caires, D. N., Carneiro, P. L. S. (2010): Curvas de crescimento em bovinos da raça Indubrasil criados no Estado do Sergipe. - Rev Ciênc Agronôm 41: 671-676.

[25] Verhulst, P. F. (1838): Notice sur la loi que la population pursuit dans son accroissement. - Correspondance Mathématique et Physique 10: 113 -121.

[26] Von Bertalanffy, L. (1957): Quantitative laws in metabolism and growth. - The Quarterly Review of Biology 32: 217 -230. 